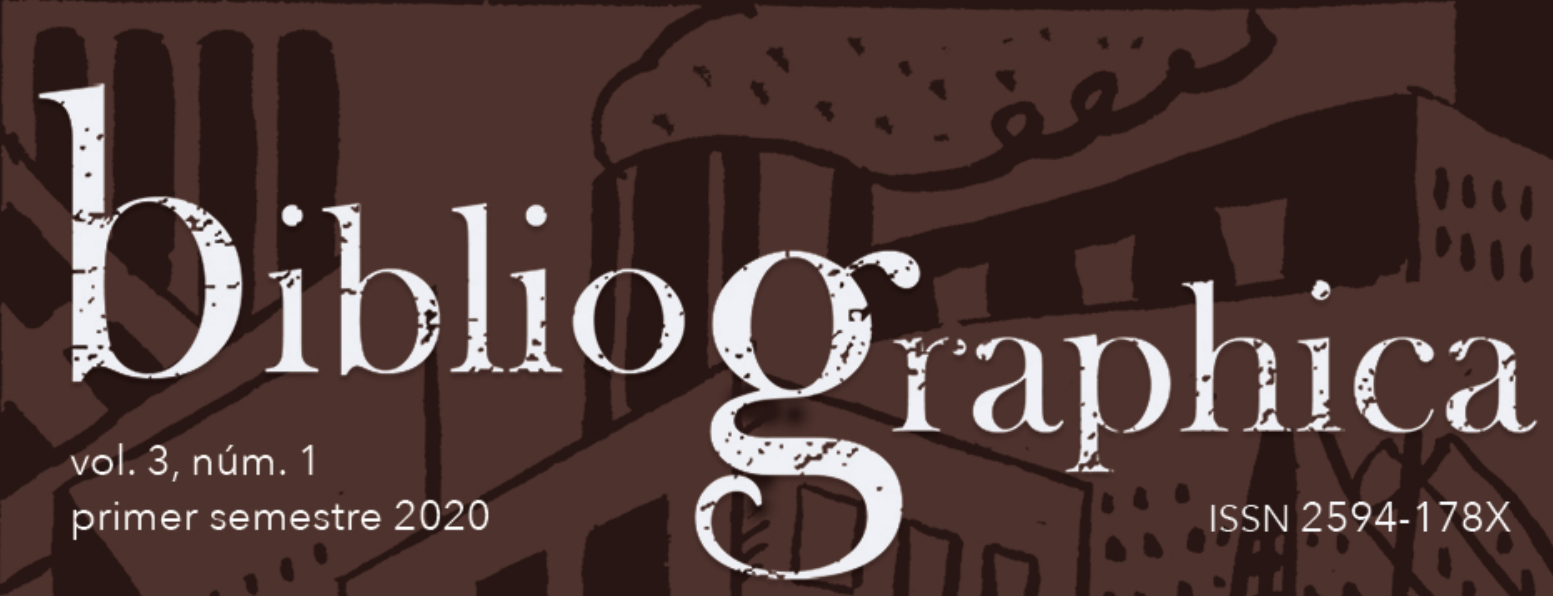




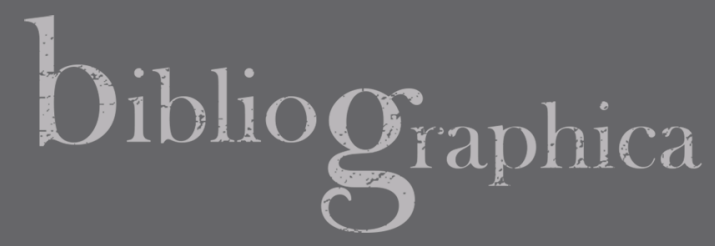

\section{"Un editor entre siglos inquiere a la historia del libro en México"}

\section{Libros.}

Tomás Granados Salinas. Historia Ilustrada de México.

México: Secretaría de Cultura, 2017, 208 pp.

ISBN: 978-607-745-760-2

\section{Freja I. Gervantes Becerril}

frejina@gmail.com

Universidad Autónoma Metropolitana-Iztapalapa

Área de Investigación en Producción Editorial, Letras Hispánicas

Recepción: 05.08.2019. Aceptación: 02.09.2019

DOI: https://doi.org/10.22201/iib.2594178xe.2020.1.59 
Con Libros, Tomás Granados Salinas continúa actualizando la tradición moderna de revalorar y difundir la historia de la producción bibliográfica en México, al mismo tiempo que se aparta de ella para cuestionarla. Si sus objetivos son discurrir una vez más sobre los acontecimientos que han dado por resultado las formas y creaciones específicas de editar y comerciar los libros en México, su alcance y destino difiere de otras obras similares por su enfoque. En este sentido, más que emprender una nueva historia del libro, el autor ha recurrido a ellas para desarrollar los asuntos que le preocupan como profesional de los libros, por lo que su tentativa ofrece una lectura renovada de los acontecimientos que bibliógrafos, historiadores y especialistas del libro han documentado de primera fuente sobre nuestra cultura escrita. De ahí que Libros sea, en todo caso, el ensayo de un editor que padece cotidianamente las condiciones periféricas y vulnerables de la industria editorial mexicana.

El recorrido selectivo e ilustrado por la historia de los libros en México que emprende el editor fundador de la colección Libros sobre Libros abarca tanto los códices prehispánicos y poshispánicos como los libros digitales que se ofrecen actualmente en la red. Cada capítulo constituye un periodo que representa un horizonte reducido a problema, es decir, una pregunta que se busca responder hurgando en el pasado para explicar los complejos escenarios del presente, cuestiones muchas veces desesperanzadoras de las condiciones que han determinado el desarrollo actual de un mercado y una industria editorial, la determinación de profesionalizar a los sujetos en sus prácticas contemporáneas de escritura, edición y comercialización y, por supuesto, la apuesta por crear públicos consumidores de libros que logren ser lectores.

Si bien los escenarios del libro en México se han caracterizado a lo largo del tiempo por su precariedad, emergencia e improvisación, el autor de Libros, lejos de parecer un pesimista, deviene en optimista irredento, contra todo pronóstico y ante la evidencia de los hechos que implican reconocer nuestras graves condiciones. Para ello, las preguntas del editor no se limitan a su experiencia, sino que en un ejercicio mayor las abre a sus lectores para que dialógicamente se inquiera a la historia del libro sobre el origen de los problemas y las asimetrías que actualmente aquejan su situación. A manera de ejemplo, a Tomás Granados le preocupa lo que a simple vista parece un absurdo, ¿por qué en un país con más de 100 millones de personas, como México, solamente existe un reducido grupo de lectores asiduos?, ¿cómo pueden aún prevalecer en la era industrial los resabios limitantes de la imprenta colonial y el control del comercio librero desde Europa, con desleales y monopólicas prácticas comerciales? Tan solo en este par de enunciaciones parecen condensarse las políticas editoriales de la cultura mexicana en materia de libros, que bien pueden extenderse a problemáticas lingüísticas e ideológicas si se considera que actualmente en México se 
hablan alrededor de 68 lenguas indígenas, con más de 300 variantes.

En Libros se narra una travesía en cinco estaciones, el trayecto es cronológico, y el asombro permanente: cada apartado envuelve una trama singular, por contradictoria, y esconde un enigma por develar. Así, en la primera estancia, "Viejos libros de aquí y de allá", se establece la permanencia de una cultura del libro en Mesoamérica con un considerable grado de estilización y funciones específicas de los códices, paralela a la de los manuscritos en Europa. Los tlacuilos, aquellos escribas dibujantes formados en una tradición para fijar la lengua y cultura indígenas, fueron los eruditos y pintores de los códices o amoxtli, en náhuatl, preservados en bibliotecas (amoxcalli). Al considerar materialmente los códices de aquí y allá bajo la mirada en paralelo -como los materiales, las formas de articulación y encuadernación, las tintas y sus principios cromáticos-, revelan más semejanzas de lo imaginable con la historia de la imprenta de Occidente y siembran la inevitable sospecha sobre su exterminio. Libros antiguos cuya belleza aterró, saberes temidos que merecieron las llamas, libros que debían sustituirse y sincretizarse para dar existencia a una nueva cultura letrada. Quizá eso explique la rapidez con la que se alojó la primera imprenta de América en la ciudad tomada, la gran Tenochtitlán, y la convivencia de los códices posteriores a la Conquista con los libros novohispanos.

El segundo capítulo, "Cosa muy útil y conveniente", recuerda la instauración de la imprenta en Nueva España y el impulso de sus promotores -el primer virrey Antonio de Mendoza y su primer obispo Juan de Zumárraga- para su misión evangelizadora, así como los claroscuros de una genealogía de impresores y tipógrafos que caracterizaron las páginas impresas de los libros coloniales a lo largo de tres siglos, empezando por las controversias sobre el enigma del primer impresor con Esteban Martín y Juan Pablos, cuyas trampas eruditas han cautivado a más de un especialista. En este capítulo, la analogía trasatlántica entre tipógrafos editores descubre en nuestro pasado la tradición que instauró Antonio de Espinosa en la historia mexicana hasta nuestros días:

Si Italia tuvo a su Manuzio y Francia su Garamond, la Nueva España contó con Espinosa como notable agente de cambio en cuanto a estilo y calidad en tipografía, diseño de páginas y uso de grabados [...] en México contamos con el revival de los caracteres tallados por Antonio y traídos al mundo contemporáneo por el punzonista digital Cristóbal Henestrosa (p. 80).

No obstante, la imprenta dependió totalmente de la Corona para sus insumos y fue controlada por la Inquisición; su producción insuficiente determinó la escasez de un público y su reducida recepción del comercio trasatlántico. A más de cinco siglos después la situación prevalece -según los datos de la Federación de Gremios de Editores de España, que revelan un des- 
equilibrio contundente- y está determinada por el flujo unidireccional del comercio y la ganancia: por un euro que México vende a España, ésta le vende 68 euros. Como editor atento y lector del pasado, Tomás Granados se ocupa especialmente del comercio de los libros durante la Colonia, busca indicios para recrear los espacios de venta, su circulación y la sociabilidad que alcanzaron estas mercancías, cuyo valor simbólico ha sido indiscutible, como omitido su valor comercial.

Desde la perspectiva editorial, Granados consigue dar equilibrio a su protagonista "el libro" en su doble naturaleza simbólica y comercial, y lo representa a cabalidad en su tercera sección intitulada "Cajones, portales, mesas, sitios electrónicos, estands". Dadas las evidentes deficiencias actuales de una red comercial del libro en México, las cuales lectores y editores padecen en direcciones opuestas, porque no se consiguen los libros o no logran alcanzar su canal adecuado y arribar al punto de venta, valdría la pena preguntarse si ante los efectos negativos del monopolio librero, las soluciones se encuentran en la profesionalización de los libreros y la preservación de sus espacios de comercio especializado, en el que proliferaría la bibliodiversidad. No cabe duda respecto de la lección histórica: producir libros ha sido y es tan importante como venderlos.

A partir de este momento el discurso de Granados opera de manera elíptica y regresa al asombro de repensar en las formas de producción que determinaron la calidad material de los códices anteriores a la Conquista, así como el valor y adquisición de sus materiales a partir del trueque. Posteriormente se observan las obras impresas exhibidas en los establecimientos del comercio de Nueva España, que se ofrecían junto con otras mercancías, incluso perecederas; asimismo se confirma la compra a ciegas de cajones de libros, entre otras mercancías, por los minoristas a los mercaderes. Estas situaciones comerciales de la Colonia estuvieron en gran medida condicionadas por el control del Santo Oficio, una tensión que revela también la coexistencia del mercado negro, la piratería, la circulación clandestina de las ideas en las obras prohibidas que dieron nacimiento a revoluciones, como la Independencia en América. En relación con los libros, es demasiado lo que se ignora u olvida sobre su comercio y distribución, los riesgos y estrategias que conlleva como factores clave para su desarrollo exitoso, y que resultan referentes valiosos para el emprendimiento y permanencia de cualquier proyecto editorial.

En el convulso y apasionante siglo XIX, los libros fueron una mercancía costosa, minoritaria y de circulación reducida. El desarrollo de la prensa y la circulación periódica a una escala mayor de sus impresos influyeron en las nuevas prácticas comerciales del libro para impulsar su comercio y producción, además de propiciar reformulaciones y la creación de géneros editoriales, así como canales de distribución más eficientes, por ejemplo la suscripción. Los 
establecimientos de venta para los libros poco a poco empezaron a diferenciarse y concentrarse, hasta que en las primeras décadas del siglo XX lograron consolidarse en los espacios exclusivos para su adquisición, librerías sin mostrador y con anaqueles abiertos al público, bibliotecas de confort que recuerdan los gabinetes de lectura del siglo anterior.

Los últimos capítulos de Libros, "De la censura a las regalías" y "El Estado editor", son quizá los que con mayor claridad plantean las preocupaciones del editor actual en México. En el primero, el valor jurídico y comercial que enmarca la vida y circulación de los libros a lo largo de su historia se expresan en fenómenos como la autoría y la regulación de la práctica comercial, ahora extendidas al mundo digital. En el último capítulo Granados Salinas concentra su pesquisa sobre la historia de los libros en el surgimiento del Estado posrevolucionario, con sus antecedentes en las gestiones de Venustiano Carranza y claramente concebidas en un proyecto editor durante la presidencia de Álvaro Obregón, cuando el Estado logró concentrar la práctica edi- torial y fundar esta industria desde sus instituciones, con la gestión del entonces secretario de Educación Pública José Vasconcelos. A esta ambiciosa empresa de la primera mitad del siglo XX se suman la fundación del Fondo de Cultura Económica y después la creación de la Comisión Nacional de Libros de Texto Gratuitos. Una actividad editorial estatal que no siempre se ha potenciado en relación armónica con la industria editorial mexicana.

A lo largo de esta travesía ilustrada por los libros en México, Tomás Granados se acompañó de eruditas y oportunas lecturas, detrás de su escritura se escuchan las voces y aportes de Joaquín García Icazbalceta, José Toribio Medina, Ernesto de la Torre Villar, Agustín Millares Carlo, Juana Zahar Vergara, Cristina Gómez Álvarez, Carmen Castañeda, Pablo Escalante Gonzalbo, Marina Garone Gravier y Manuel Suárez, entre muchos otros estudiosos y amantes del impreso. Libros es ya uno de los títulos imprescindibles para quien desee introducirse en el mundo del libro y para aquellos que contribuyen todos los días al pensamiento de una cultura editorial en México. $* b$ 